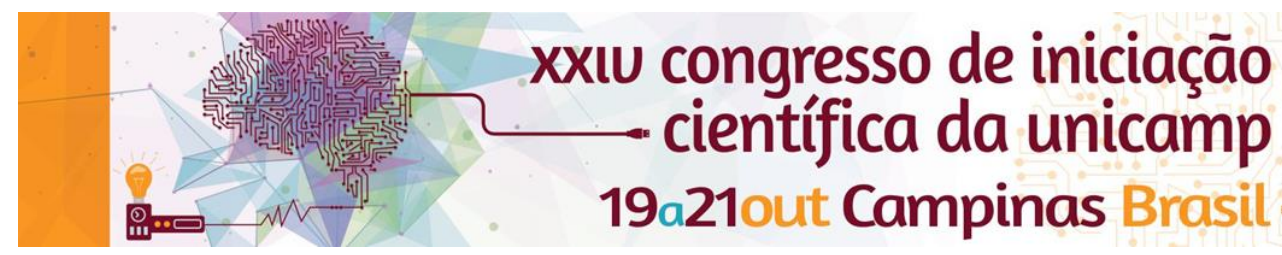

\title{
EFEITOS DA OBESIDADE MATERNA E DA REEXPOSIÇÃO À DIETA HIPERLIPÍDICA SOBRE A SINALIZAÇÃO DE INSULINA NO MÚSCULO ESQUELÉTICO DE CAMUNDONGOS ADULTOS
}

\section{Monique de Souza*, Thaís de Fante, Adriana Souza Torsoni.}

\section{Resumo}

Já se sabe que a obesidade materna induzida pelo consumo de dieta hiperlipídica é capaz de levar à programação metabólica da prole, predispondo ao desenvolvimento do fenótipo obeso. Durante o processo inflamatório crônico e de baixo grau induzido pela obesidade, proteínas são ativadas e agem na cascata de sinalização da insulina, bloqueando o sinal e levando ao desenvolvimento de resistência. Dessa forma, considera-se importante investigar os efeitos potenciais da programação metabólica em prejudicar a sinalização de insulina no músculo esquelético da prole de mães obesas, seja quando essa prole é alimentada apenas com dieta controle ou exposta diretamente à dieta hiperlipídica na vida adulta.

\section{Palavras-chave:}

Dieta hiperlipídica, resistência à insulina, musculo esquelético.

\section{Introdução}

A obesidade é uma enfermidade que acomete grande parte da população mundial. Recentemente tem sido estabelecida uma relação entre obesidade materna e programação metabólica na prole. Estudos sugerem que a prole de mães com obesidade induzida por dieta hiperlipídica $(\mathrm{DH})$ esteja mais predisposta ao desenvolvimento do fenótipo obeso e suas comorbidades na vida adulta. Relacionada a esse quadro, a resistência à insulina é um fator frequentemente presente, podendo levar ao desenvolvimento do diabetes mellitus tipo 2. Durante o processo inflamatório de baixo grau observado na obesidade, proteínas serina quinases são ativadas, dentre elas JNK e IKK, e agem na cascata de sinalização da insulina, bloqueando o sinal hormonal e levando ao desenvolvimento de resistência. Nesse cenário, o presente estudo teve como objetivo avaliar os efeitos desencadeados pela programação metabólica e pela reintrodução de $\mathrm{DH}$ na fase adulta sobre a sinalização de insulina no músculo esquelético da prole de mães alimentadas com $\mathrm{DH}$ durante a gestação e lactação.

\section{Resultados e Discussão}

A prole de mães obesas $(\mathrm{PHH})$ e a prole de mães controle $(\mathrm{PCH})$, alimentadas com dieta hiperlipídica na vida adulta, apresentaram maior ganho de peso em relação aos outros grupos avaliados. No entanto, desde o momento da exposição à dieta, o ganho de peso no grupo $\mathrm{PHH}$ foi mais acentuado. Além disso, os animais $\mathrm{PHH}$ apresentaram maior adiposidade, ingestão alimentar, menor tolerância à glicose e sensibilidade à insulina.

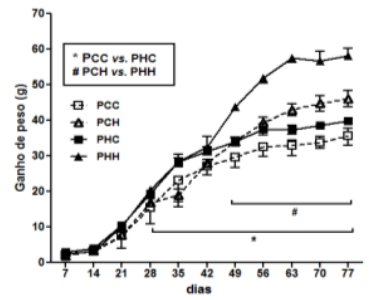

Figura 1. Evolução do peso da prole.

O grupo PHC apresentou maior ativação de marcadores inflamatórios (JNK e IKK), quando comparado ao grupo PCC. Além disso, todos os animais que tiveram contato direta ou indiretamente com $\mathrm{DH}$ apresentaram prejuízo na sinalização da insulina, evidenciado pela menor fosforilação de IRS-1 e AKT no músculo esquelético.
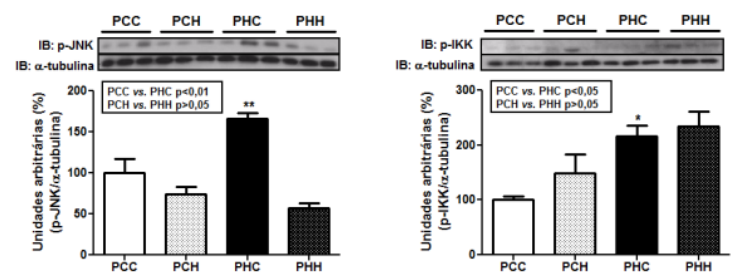

Figura 2. Conteúdo protéico de JNK e IKK no músculo (Soleus) da prole.
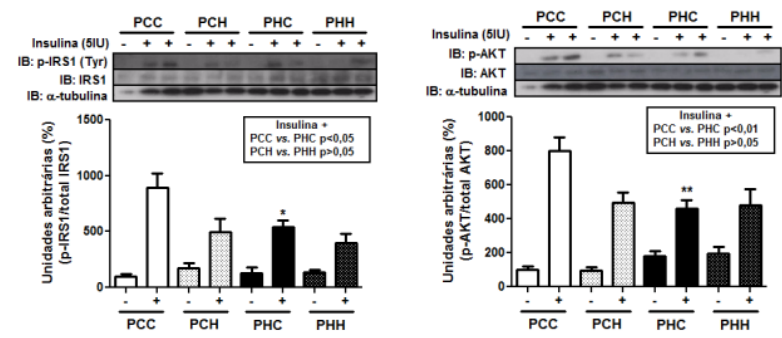

Figura 3. Conteúdo protéico de IRS-1 e AKT no músculo (Soleus) da prole.

\section{Conclusão}

Apesar da exposição da prole de mães obesas à DH na vida adulta não ter sido um fator agravante para a via de sinalização de insulina, os prejuízos metabólicos relacionados ao desenvolvimento do fenótipo obeso estão mais agravados no grupo $\mathrm{PHH}$ quando comparados ao grupo $\mathrm{PCH}$, levando a acreditar que a associação entre obesidade materna e consumo de $\mathrm{DH}$, mesmo que apenas na vida adulta, é capaz de propiciar uma resposta exagerada ao desenvolvimento do fenótipo obeso. Esses dados reforçam a importância da alimentação materna adequada durante o desenvolvimento da prole, já que os prejuízos desencadeados podem ser determinantes mesmo em consumo de dieta controle.

\section{Agradecimentos}

CNPq e FAPESP (Proc. n. 2013/12003-4) 